\title{
Pain and Distress in Cancer Patients
}

\author{
Burger-Szabo Anna*, Gabos-Grecu Marieta, Moica Theodor, Finta Hajnal, Ferencz Melinda, \\ Gabos-Grecu Cristian, Gabos-Grecu losif
}

University of Medicine and Pharmacy Tirgu Mures, Romania

Background: A significant number of patients with cancer suffer from anxiety and depressive disorder. Perceived emotional distress, anxiety and depressive symptoms are significantly more frequent in cancer patients with pain than in patients without pain. Despite their high prevalence cancer pain and distress are frequently undertreated.

Material and method: Thirty two oncology patients were included in the study who were receiving concurrent oncologic and pain treatment in the Oncology Clinic TgMures. Patient demographic and clinical information was obtained from medical records and patient report. Patients were screened for pain scores using the Visual Analog Scale and distress scores, using the Distress Thermometer.

Results: The gender proportion of the sample is: $38 \%$ female, $62 \%$ male. More than $75 \%$ of the sample was over 50 years of age , and more than half of the patients (59.3\%) had metastatic disease. Significant decreasing trend were seen for pain score difference before and after the pain treatment was reassessed (dosage increase or conversion) $(p<0.0001)$, and decreasing trend seen for distress score ( $p<0.0001)$ also. Conclusions: Pain and distress occurred concomitant in this population. An adequate pain management and pain reassessment contributes to improve the cancer patient emotional distress score, anxiety and depressive symptoms. An accurate screening instrument can facilitate the recognition of patients who needs further assessment and psychiatric treatment.

Keywords: cancer pain, distress, anxiety, depression

Received: 09 December 2014 / Accepted: 04 June 2015

\section{Introduction}

The cancer-related pain is common, no less than $79 \%$ of the patients suffering from cancer in Romania reported pain (EPIC study) [1]. Of these, $94 \%$ of the patients considered their pain experience to be significant, moderate to severe pain (rated 5 to 10 on the pain scale). Despite the availability of medicines that can control pain, cancer pain is often inadequately treated [2-6]. Sixty-four percent of the patients using prescribed analgesia reported inadequate pain control.

Pain is a multidimensional phenomenon that is the result of a complex interaction between psychological, cognitive, social and other factors. Patients experiencing pain may connect it with the progression of disease or a poor prognosis, and this may increase their anxiety, uncertainty, and depression [7].

The advances in pain research are reflected in international recommendations to use psychosocial adjuncts for cancer pain management by agencies such as the World Health Organization, the American Pain Society, the Agency for Health Research and Quality (formerly called the Agency for Health Care Policy and Research), and the International Association for the Study of Pain [8-12]. All patients experience some level of distress associated with the diagnosis of cancer and the effects of its treatment regardless of the stage of the disease. The improved cancer treatment options are associated with long time side ef-

* Correspondence to: Anna Burger-Szabo

E-mail: burgerani@yahoo.com fects: fatigue, pain, anxiety and depression are the most frequent that interfere with the daily activity [13].The prevalence of psychological distress in individuals varies by the type and stage of cancer as well as the patient's age, gender and race[14,15].

The most common types of psychological disorders are anxiety and depression. A number of studies were published in the last decades on this topic. One of the most popular and often quoted study is the one from Derogatis et al. that shows the prevalence of psychiatric disorders. Nearly $50 \%$ of cancer patients had a psychiatric diagnosis, and most of them had reactive depression, adjustment disorders and a smaller number had other disorders including delirium and anxiety disorders. So, many of the patients who have cancer and have a psychiatric disorder, they will probably have anxiety and an adjustment disorder.

\section{Materials and methods}

Thirty-two oncology patients who were receiving concurrent oncologic and pain treatment in the Oncology Clinic Tirgu Mures between October 2013 and June 2014, were included in the study. The patients were asked to complete the Distress Thermometer, a rapid screening tool for distress, and the Visual Analog Scale, the universal screening and comprehensive pain assessment tool. Patients completed the Distress Thermometer and the Visual Analog Scale during their oncology treatment in the hospital, noted as visit 1 , and during the next visit to the hospital, noted as visit 2. Patient demographic and clinical information was obtained from medical records and patient report. 


\section{Participants}

Participants included cancer diagnosed patients, treated with chemotherapy or radiotherapy in Oncology Clinic of Tirgu Mures.

\section{Measures}

\section{Emotional Distress}

The Distress Thermometer (DT), endorsed by the National Comprehensive Cancer Network (NCCN) Psychosocial Distress Practice Guidelines Panel, is a brief self-report screening tool that measures sources of distress and distress levels over the past week. The DT is a visual analogue scale with scores from 0 (no distress) to 10 (extreme distress) and a midpoint anchor labeled "moderate distress". In accordance with NCCN guidelines, we considered a DT score of $>5$ as an indication of clinically significant distress.

\section{Pain assessment}

According to data published in the literature, at least two types of cancer-related pain can be recorded in patients with advanced cancer, and they can derive from different etiologies $[16,17]$. The vast majority of cancer patients (69\%) related an impaired ability to function as a result of their worst pain [18]. As for an effective and individualized treatment, a proper and regular self-reporting assessment of pain is required, several assesment scales have been proposed, most used standardized scales being represented by [19]: visual analog scales (VAS), verbal rating scales (VRS) and numerical rating scales (NRS). According to WHO guidelines, opioid analgesics are the standard of care in analgesic therapy. According to their ability to control pain, they are classified in mild, mild-moderate or moderate to severe intensity. However, the intensity of pain is frequently reported as mild, moderate or severe and the pain is scored accordingly on an VAS respectively as $\leq 4$, from 5 to 6 , and $\geq 7$ [20].

\section{Statistical Analyses}

The levels of VAS and distress among cancer patients were represented in percentages and Chi-square test was used to identify potential factors influencing the prevalence of distress and pain. The significance level was 0.05 . Data were analyzed using SPSS software.

\section{RESULTS}

\section{Demographic and Clinical Characteristics}

The sample consisted of 32 patients, with chronic cancer pain, majority over 65 years (see Figure 1 for age and gender distribution). $92 \%$ of the high pain group (VAS >7, on a $0-10$ scale) received surgical intervention, and $88 \%$ of the high pain group had metastatic stage (see Figure 2 for participants cancer localization and status).

Patients with cancer related pain were defined as patients with a diagnosis of cancer experiencing pain from direct tumor involvement and a form of cancer treatment,

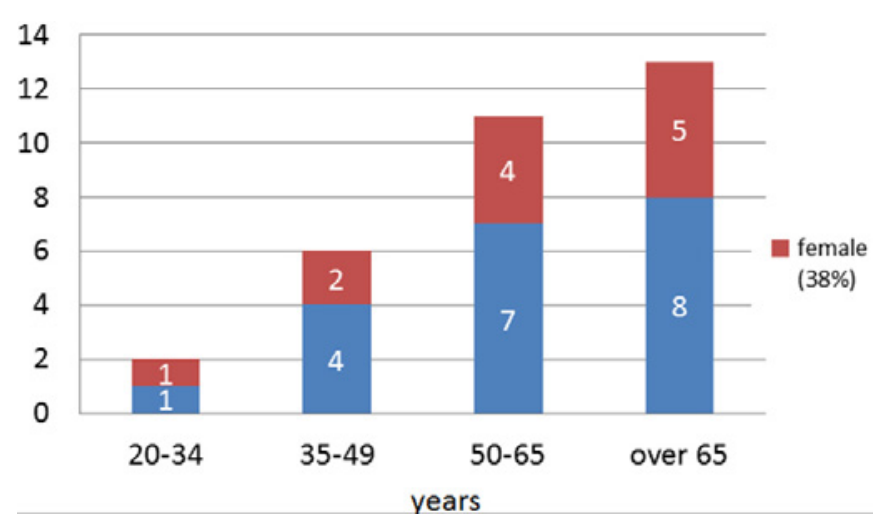

Fig. 1. Distribution of age and gender

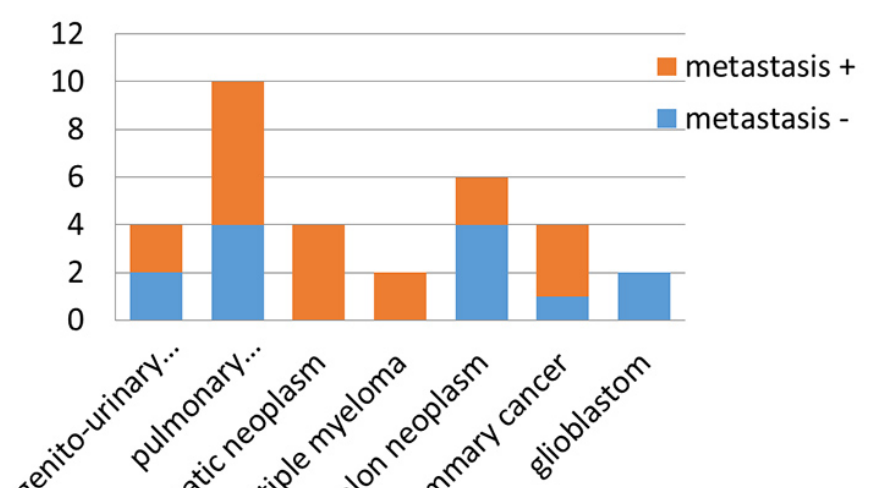

Fig. 2. Participants cancer localization and status

confirmed by the oncologist. The high pain group was defined as the one with the score $\geq 7$ on the Visual Analog Scale (see Table 1.for the patient demographic and medical characteristics).

There is a significant difference on the VAS scale between the $1^{\text {st }}$ and $2^{\text {nd }}$ visit, before the pain assessment/reassessment and after (mean visit $1=5.5$, visit $2=2.3, \mathrm{P}<0.001$ ). $49 \%$ of patients rating themselves with $>7$, which indicated high level pain. On the Distress Thermometer scale $62 \%$ rated $>5$, which indicated meaningful level of distress (see Table 2 for pain and distress difference after intervention).

\section{DISCUSSIONS}

In this article we present our findings, regarding the concomitant presence of pain and emotional distress in cancer patient. Significant decreases in pain and in distress scores were found from visit 1 to visit 2, before and after the pain treatment was reassessed (dosage increase or conversion).

The initiation of analgesic treatment should be done already during the diagnostic evaluation and should be performed in accordance with the principles indicated by the WHO analgesic ladder, appropriate for the severity of pain [II, B]. A satisfactory relief of pain can be achieved by most of cancer patients using a combined approach that includes primary antitumor treatments, systemic analgesic therapy using opioid analgesics, eventually combined with nonopioid drugs such as paracetamol or with non-steroidal 
Table I. Pacient demographic and medical characteristics

\begin{tabular}{lccc}
\hline Variable & High pain & Low pain & P value \\
\hline Demographic & & & \\
Percentige male & $55,4 \%$ & $66,5 \%$ & NS \\
Percentige married & $43 \%$ & $38 \%$ & NS \\
Percent employed & $5 \%$ & $27 \%$ & 0,001 \\
Medical & & & \\
\hline Number with primary cancer & & & \\
Breast & 2 & 2 & \\
Lung & 8 & 2 & \\
Colon & 4 & 2 & \\
Pancreas & 4 & 1 & \\
Cervix & 2 & 2 & \\
Other & 2 & 1 & \\
Percentge with metastasis & $88 \%$ & $57 \%$ & 0,001 \\
Percentige who received surgery & $92 \%$ & $87 \%$ & NS \\
Percentige who received chemotherapy & $45 \%$ & $51 \%$ & NS \\
Percentage who received radiation & $50 \%$ & $50 \%$ & NS \\
\hline
\end{tabular}

Table II. VAS and Distress difference after intervention

\begin{tabular}{lccc}
\hline Variable & Visit 1 & Visit 2 & P value \\
\hline VAS & & & \\
High & $49 \%$ & $4 \%$ & \\
Moderate & $33 \%$ & $9 \%$ & \\
Low & $18 \%$ & $87 \%$ & 0,001 \\
\hline Distress & & & \\
High & $62 \%$ & $15 \%$ & \\
Moderate & $29 \%$ & $41 \%$ & \\
Low & $9 \%$ & $44 \%$ & 0,003 \\
\hline
\end{tabular}

anti-inflammatory drugs (NSAIDs) or with adjuvant drugs $[21,22]$,associated with other non-invasive techniques such as psychological or rehabilitative interventions. At the same time, extremely important could be the assessment of the associated psychosocial distress, which has been proved to be strongly associated with cancer pain [23] and may amplify the perception of pain-related distress in a vicious circle in which, similarly, an inadequate control of pain may cause significant psychological distress.

Psychosocial distress has to be assessed because it is strongly associated with cancer pain [23]. In fact psychosocial distress may amplify the perception of pain-related distress and, similarly, inadequately controlled pain may cause substantial psychological distress.

The evidence for a relationship between psychosocial factors and chronic cancer pain is considered Strong for psychological distress. Spiegel et al.found a significant association between pain intensity and psychological distress, but not between pain intensity and depression [24]. They also found a significant association between pain frequency and depression but not between pain frequency and psychological distress. Their conclusion that pain preceded depression was based in part on the finding that a history of depression was more prevalent for the Low Pain Group than for the High Pain Group. There is evidence to support this direction. In a review of the literature to examine the relationship between depression and chronic pain, Fishbain and colleagues found that there was greater support for the hypothesis that depression is a consequence of chronic pain rather than the hypothesis that depression is an antecedent to chronic pain [25].

For psychological distress, there is strong evidence on which to make a clinical recommendation, and the prevalence of psychological distress among cancer patients is high [26-29]. Comprehensive chronic pain assessment should include routine screening of psychological distress, because brief measures are available and interventions are effective [23].

\section{Conclusions}

Pain and distress occurred concomitant in this population. An adequate pain management and pain reassessment contributes to improve the cancer patient emotional distress score, anxiety and depressive symptoms. An accurate screening instrument can facilitate the recognition of patients who needs further assessment and psychiatric treatment.

\section{References}

1. Breivik H, Cherny $\mathrm{N}$, Collett $\mathrm{B}$, et al. Cancer-related pain: A panEuropean survey of prevalence, treatment, and patient attitudes. Annals of Oncology. 2009;20:1420-1433.

2. Lesage P, Portenoy RK. Trends in cancer pain management. Cancer Control. 1999;6:126-145.

3. Kelsen DP, Portenoy RK, Thaler HT, et al. Pain and depression in patients with newly diagnosed pancreas cancer. J Clin Oncol. 1995;13:748-755.

4. Portenoy RK. Cancer pain: epidemiology and syndromes. Cancer. 1989;63(Suppl):2298-2307.

5. Warncke T, Breivik H, Vainio A. Treatment of cancer pain in Norway: a questionnaire study. Pain. 1994;57:109-116.

6. Sapir R, Catane R, Strauss-Liviatan N, Cherny NI. Cancer pain: knowledge and attitudes of physicians in Israel. J Pain Symptom Manage. 1999;17:266-276.

7. Levy $\mathrm{MH}$, Chwistek M, Mehta RS. Management of chronic pain in cancer survivors. Cancer J. 2008;14:401-409.

8. World Health Organization. Cancer pain relief and palliative care. Report of a WHO expert committee (World Health Organization technical report series 804). Geneva. Switzerland. World Health Organization, 1990.

9. American Pain Society Quality of Care Committee. Quality improvement guidelines for the treatment of acute pain and cancer pain. JAMA. 1995;274:1874-1880

10. ASCO. Cancer pain assessment and treatment curriculum guidelines. $J$ Clin Oncol. 1992;10:1976-1982.

11. Agency for Health Care Policy and Research. Management of cancer pain. Patient guide. Oncol Nurs Forum. 1994;21:1232-1238.

12. Jacox A, Carr DB, Payne R, et al. Management of cancer pain. Clinical practice guideline. No 9. AHCPR Publication No. 94-0592. Rockville, MD: Agency for Health Care Policy and Research, U.S. Department of Health and Human Services, Public Health Service, March 1994.

13. Carr D, Goudas L, Lawrens D et al. Management of cancer symptoms. Pain, depression and Fatigue. Evidence Report/Technology Assessment no 61. AHRQ Publication no 02-E032.

14. Traeger L, Cannon S, Keating NL, et al. Race by Sex Differences in Depression Symptoms and Psychosocial Service Use Among NonHispanic Black and White Patients With Lung Cancer. JCO. 2014;107113.

15. Levy $\mathrm{MH}$, Chwistek $\mathrm{M}$, Mehta RS. Management of chronic pain in cancer survivors. Cancer J. 2008;14:401-409.

16. Higginson IJ, Murtagh F. Cancer pain epidemiology. In: Bruera E, Portenoy RK (eds). Cancer Pain. Assessment and Management. Vol. 3. Cambridge. Cambridge University Press. 2010;37-52.

17. Portenoy RK, Koh M. Cancer pain syndromes. In: Bruera E, Portenoy RK (eds).Cancer Pain. Assessment and Management, Vol. 4. Cambridge. Cambridge University Press, 2010;53-88.

18. Larue F, Colleau SM, Brasseur L, Cleeland CS. Multicentre study of cancer pain and its treatment in France. BMJ. 1995;310:1034-1037.

19. Caraceni A, Cherny N, Fainsinger $R$ et al. The Steering Committee of the EAPC Research Network. Pain measurement tools and methods 
in clinical research in palliative care: recommendations of an expert working group of the European Association of Palliative Care. J Pain Symptom Manage. 2002;23:239-255.

20. Serlin RC, Mendoza TR, Nakamura Y, Edwards KR, Cleeland CS. When is cancer pain mild, moderate or severe? Grading pain severity by its interference with function. Pain. 1995;61:277-284.

21. Lussier D, Portenoy RK. Adjuvant analgesic drugs. In: Bruera E, Higginson IJ, Ripamonti C, von Gunten C (eds). Textbook of palliative medicine. London. Edward Arnold Publishers. 2006;402-414.

22. Ripamonti C, Bandieri E. Cancer pain. Crit Rev Oncol Hematol. 2009;70:145-149.

23. Zaza C, Baine N. Cancer pain and psychosocial factors: a critical review of the literature. J Pain Symptom Manage. 2002;24:526-542.

24. Spiegel D, Sands S, Koopman C. Pain and depression in patients with cancer. Cancer. 1994;74:2570-2578.

25. Fishbain DA, Cutler R, Rosomoff HL, Rosomoff RS. Chronic painassociated depression: antecedent or consequence of chronic pain? A review. Clin J Pain. 1997;13:116-137

26. Farber JM, Weinerman $\mathrm{BH}$, Kuypers JA. Psychosocial distress in oncology outpatients. J Psychosoc Oncology. 1984;2:109-118.

27. Okamura H, Watanabe T, Narabayashi M, et al. Psychological distress following first recurrence of disease in patients with breast cancer: prevalence and risk factors. Breast Cancer Res Treat. 2000;61:131137.

28. Spiegel D. Psychosocial aspects of breast cancer treatment. Semin Oncol. 1997;24(Suppl 1):S1-S47.

29. Zabora J, Brintzenhofeszoc K, Curbow B, et al. The prevalence of psychosocial distress by cancer site. Psychooncology. 2001;10:19-28. 